\title{
Anterolateral Ligament (ALL) - Myth or Reality?
}

\author{
Mihai Roman', Octav Russu², Radu Prejbeanu ${ }^{3}$, Adrian Todor ${ }^{4}$, Vlad Predescu ${ }^{5}$, Bogdan \\ Codorean ${ }^{5}$, Tiberiu Bățagă², Radu Fleaca1 \\ 1 “Victor Papillan” Faculty of Medicine, "Lucian Blaga” University, Sibiu, Romania \\ 2 University of Medicine and Pharmacy, Tîrgu Mureș, Romania \\ 3 "Victor Babeș" University of Medicine and Pharmacy, Timișoara, Romania \\ 4 "Iuliu Hațieganu" University of Medicine and Pharmacy, Cluj-Napoca, Romania \\ 5 "Carol Davila" University of Medicine and Pharmacy, Bucharest, Romania
}

\section{CORRESPONDENCE}

\section{Mihai Roman}

Str. Lucian Blaga nr. 2A

550169 Sibiu, Romania

Tel: +40 269212320

E-mail: mihaidanroman@yahoo.com

\section{ARTICLE HISTORY}

Received:

Accepted:

Octav Russu • Str. Gheorghe Marinescu nr. 38 , 540139 Tîrgu Mureș, Romania. Tel: +40 265215551. E-mail: octav@genunchi.ro

Radu Prejbeanu • P-ța Eftimie Murgu nr. 2, 300041 Timișoara, Romania. Tel: +40 256204 400. E-mail: raduprejbeanu@gmail.com

Adrian Todor • Str. Emil Isac nr. 13, 400023 ClujNapoca, Romania. Tel: +40 264406 843. E-mail: adi. todor@yahoo.com

Vlad Predescu • B-dul Eroii Sanitari nr. 8, 050474 Bucuresti, Romania. Tel: +40 213180 719. E-mail: vladpredescu001@gmail.com

Bogdan Codorean • B-dul Eroii Sanitari nr. 8, 050474 București, Romania. Tel: +40 213180 719. E-mail: dr.codorean@traumatologie-sportiva.ro

Tiberiu Bățagă • Str. Gheorghe Marinescu nr. 38 540139 Tîrgu Mureș, Romania. E-mail: tbataga@ gmail.com

Radu Fleaca • Str. Lucian Blaga nr. 2A, 550169 Sibiu, Romania. Tel: +40 269212 320. E-mail: r eaca@ yahoo.com

\begin{abstract}
Although the anterolateral ligament (ALL) was described a long time ago, recent research shows a lot of interest regarding this structure. There is a high variability concerning its anatomy, especially its capsular/extracapsular situation and insertion sites. There is also some controversy about its ligamentous structure. It seems that it has a biomechanical role in restricting anterior tibial translation and internal rotation. The ALL complex seems to have a clinical significance, and a relationship with the pivot shift has been described. Although there are promising results recently, the surgical techniques of ALL reconstruction, in addition to anterior cruciate ligament reconstruction, have to be further investigated. A precise indication algorithm and patient selection criteria need to be established.
\end{abstract}

Keywords: anterolateral ligament (ALL), anterolateral complex, anterior cruciate ligament $(\mathrm{ACL}), \mathrm{ACL}$ reconstruction

\section{INTRODUCTION}

The anterolateral ligament (ALL) has been recently brought into attention after the paper of Claes received considerable public and media attention. ${ }^{1}$ A large debate regarding the ligament's anatomical landmarks, histology, functional role, best method of surgical reconstruction, and even its actual existence was generated. Although a final verdict was not yet achieved, this research enhanced our knowledge to the benefit of our patients.

However, this structure is far from new. Segond first described it in 1879, as a reinforcement of the lateral joint capsule by fibers of the iliotibial band, and the avulsion fracture of the tibial plateau was named the "Segond fracture". ${ }^{2}$ Then, in 1948, Last named it "short lateral ligament". ${ }^{3}$ In 1976, Jack Hughston ${ }^{4}$ described the anterolateral structures and the middle third of the lateral capsular ligament, and in 1982 Werner Muller ${ }^{5}$ identified it as the lateral femorotibial ligamentous 
attachment. In 1986, Terry showed that there is a "capsulo-osseous layer" of the iliotibial band, while LaPrade described it as a "mid-third lateral capsular ligament" and included it in the so-called "anterolateral complex". ${ }^{6,7} \mathrm{Fi}$ nally, Vieira named this structure as we know it today "anterolateral ligament". ${ }^{8}$

Anterior cruciate ligament (ACL) surgical techniques have evolved during the years, but residual pivot shift remains a concerning issue. Therefore, more interest was addressed to the anterolateral peripheral structures. In the last years there was a large amount of research regarding the ALL; however, no definitive consensus regarding this structure has been achieved. ${ }^{1,9-14}$

\section{VARIABILITY}

Due the conflicting results that were published, some confusion is still present. The ALL seems to have a certain variability that occurs in at $33-97 \%$ of the human population. ${ }^{1,4,15,16}$ Whether the ALL is absent from a specimen or has simply been obliterated or overlooked can be due to the multiple dissection techniques. ${ }^{17}$ The impact of an ALL absence, even if only unilateral, needs to be investigated in clinical and imaging studies to finally clarify its importance. ${ }^{18}$

\section{CAPSULAR VERSUS EXTRACAPSULAR}

There are studies that identify the ALL as a capsular structure with attachments to the lateral meniscus. ${ }^{1,19}$ In contrast, other studies support the idea that it is an extra-capsular structure originating from the iliotibial tract, with no relation to the meniscus. ${ }^{10}$

The iliotibial tract consists of an $8 \mathrm{~cm}$ wide collagen structure, which originates from the iliac crest and iliac spine. At knee level, fibers from the iliotibial tract reach the patella (retinaculum), while others reach the septum intermusculare. The distal insertion is on Gerdy's tubercle. There are three layers: superficial, deep, and capsulo-osseous. ${ }^{12}$ The deep layer consists of fibers that reach the intermuscular septum at $6 \mathrm{~cm}$ proximal to the lateral epicondyle and anchor the iliotibial tract on the femur (Kaplan fibers). ${ }^{20}$

The capsulo-osseous layer consists of the fibers that originate cranially and posterior of the lateral epicondyle and insert on the tibia, posterior from the Gerdy's tubercle. These fibers correspond to the so-called ALL. ${ }^{21}$

Regarding the relationship to the lateral collateral ligament (LCL), the ALL is described as being superficial to the LCL. ${ }^{22}$ Many ALL reconstruction techniques have used a graft passing deep to the LCL, which could explain the over-tightening and the sub-optimal results seen with these methods. ${ }^{23}$ Other researchers consider that the ALL and the deep capsulo-osseous fibers of the iliotibial tract are in fact one and the same structure. ${ }^{21}$

The Anterolateral Ligament Expert Group concluded in a recent paper that there is a consensus that the ALL is a triangular, anterolateral structure found deep to the iliotibial band, admitting that there is a lot of debate concerning the exact specifications of the ligament. ${ }^{24}$

\section{LENGTH, THICKNESS, WIDTH}

There is also a variability regarding the length of this structure, from 37 to $59 \mathrm{~mm} .{ }^{10,19}$ The width seems to be less than $10 \mathrm{~mm} .1,16,22,23$ The thickness also presents great variability - from $0.87 \mathrm{~mm}$ to $2-3 \mathrm{~mm} .{ }^{15,23}$ This variability depends on the dissection technique. The structures are difficult to be separated. ${ }^{23}$

\section{INSERTION}

There is some controversy regarding the femoral and tibial insertions of the ALL. Claes and Bellemans (2013) found that the ALL originates at the lateral epicondyle of the femur, near the origin of the LCL, crosses the joint, attaches to the lateral meniscus, and inserts at the anterolateral aspect of the proximal tibia between the Gerdy's tubercle and the fibular head. ${ }^{1}$ Following this article, many authors performed anatomical studies, trying to define exactly the macro- and microscopic landmarks of this structure.

Vincent et al. (2012) reported the origin to be the lateral femoral condyle. ${ }^{15}$ Other authors reported slightly different insertion points. The different results can be related to the anatomical differences of the specimens, but also on the preparation methods. However, the majority of researchers conclude that the femoral insertion point lies posterior from the lateral epicondyle, and the tibial insertion is located just posterior to the mid-point of Gerdy's tubercle and fibular head. ${ }^{9}, 14,23$

The ongoing controversy that surrounds this structure reveals the difficulty of understanding the peripheral anatomy. It is not always possible to clearly define these structures, that is why one can discuss about complexes (posterolateral, anterolateral, posteromedial, anteromedial) rather than well-defined single units. $5,21,26$

Although most studies show that the anatomy and topography of the ALL seems to be highly variable, they also underline that it is consistent within certain limits. ${ }^{18}$

Thus, it is a reality that this structure exists. But is it truly a ligament or, similarly to the glenohumeral ligaments of 
the shoulder, just a thickening of the capsule that is part of an anterolateral complex?13

\section{HISTOLOGY}

Histological analysis from certain studies revealed characteristics of ligamentous tissue, and immunohistochemistry identified a network of peripheral nerves, suggesting a proprioceptive function of the ALL. ${ }^{26,27}$ Guenther $e t$ al. stated that, histologically, the collagenous structure of the ALL is significantly different from the LCL, thus questioning the ligamentous origin of the ALL. Parts of the anterolateral capsule are organized into individual bundles, most likely a combination of multiple thickenings of the capsule, and not a homogenous ligamentous entity such as the ACL or LCL. ${ }^{22,28}$ Thus, although there are some similarities between the ALL's structure and ligaments, it seems that the ALL does not fulfill the necessary criteria to be called a ligament.

\section{FUNCTION}

Internal rotational stability of the tibia is mainly restricted by the ACL, but other anatomical structures (the anterolateral complex, or the posterior horn of the meniscus) also act as secondary stabilizers. ${ }^{29,30}$

Regarding the function of the ALL, Terry et al. suggested that the anterolateral structures may play a role as a rotational knee stabilizer. ${ }^{31}$ The ALL fibers seem to stabilize the internal rotation of the knee and the anterior translation of the lateral tibia plateau, extra-articular, together with the ACL, which is the most important intra-articular contributor to rotatory knee stability. $1,32-35$

Drews et al. concluded that the ALL is supporting the ACL against internal tibial loads to a minor degree, and that there is no apparent relationship between the ALL and the pivot shift. Therefore, ALL reconstruction cannot be recommended at the moment without further biomechanical investigations. ${ }^{36}$ From a biomechanical point of view, internal rotation of the knee is better controlled by a lateral extra-articular structure compared to the centrally located ACL because of a longer lever arm..$^{37,38}$

Cadaveric studies showed that starting with 30 degrees of flexion, the deep capsulo-osseous fibers of the iliotibial tract play an important role regarding the rotational stability of the knee, while the ALL is just of secondary importance. ${ }^{12}$ Other studies showed that sectioning of the ALL in addition to the ACL, in cadaver specimens, enhanced the pivot shift significantly. ${ }^{1}$ Monaco et al. suggested that the anterolateral structures play even a larger role than the posterolateral bundle of the ACL in controlling rotational stability. 39

Despite the extensive research on the ALL, there is no consensus regarding its structure and biomechanical function. It seems that the ALL is a stabilizer against internal tibial rotation, particularly at flexion angles greater $30 \mathrm{de}-$ grees, and rupture of this structure/complex may be involved in the pathogenesis of a high-grade pivot shift. ${ }^{40}$

The consensus of the ALL Expert Group stated that the mean load to failure is around $180 \mathrm{~N}$, the mean stiffness is $31 \mathrm{~N} / \mathrm{mm}$, and the ALL acts as a restraint for the internal rotation of the tibia and affects the pivot shift in the ACLdeficient knee. ${ }^{24}$

\section{THE SEGOND FRACTURE}

Segond described the avulsion fracture of the tibial plateau as the "Segond fracture" back in $1879 .{ }^{2}$ This is considered a pathognomonic radiographic feature for an ACL injury. ${ }^{41}$ The anatomic structure responsible for the Segond fracture is not yet defined, although the suggestions include the anterolateral capsule, the anterior oblique band of the fibular collateral ligament, the iliotibial band, the short head of the biceps femoris, and the ALL. ${ }^{10,41,42}$

There is some evidence that the load of the ALL and anterolateral complex increases during ACL injury, and these structures might be responsible for the Segond fracture. Therefore, while evaluating the injured knee, one should closely evaluate the anterolateral structures as well. $1,25,43,44$

\section{CLINICAL AND SURGICAL SIGNIFICANCE}

Before modern ACL reconstruction techniques were developed, isolated lateral extra-articular procedures were used as the standard surgical techniques in patients with ACL insufficiency. These procedures were non-anatomic, reproduced the biomechanics poorly, and resulted in residual instability and over-constraint of the lateral compartment (with secondary osteoarthritis), thus being abandoned. ${ }^{40,45}$

Isolated ACL ruptures do not produce an increased pivot shift, but additional disruption of the anterolateral structures generates a high-grade pivot shift. ${ }^{39,46}$ In the last years, several anterolateral stabilizing techniques were described in order to address this issue.

The exact indication remains uncertain, because there is no study that fully proved that anatomic ALL reconstruction, in addition to the ACL reconstruction, adds real benefits. It seems that there is only a theoretical advantage related to the ALL reconstruction. ${ }^{47}$ 
Although there are a large number of studies and many debates regarding this topic, the majority of experts accept some potential indications for ALL reconstruction, based on the severity of injury: patients with high-grade pivot shifts, selected revision cases, and some high-level pivoting sports. More studies are needed to establish adequate treatment algorithms based on the individual anatomy of the patient. ${ }^{48-51}$

\section{CONCLUSION}

In our opinion, the key points in understanding the ALL structure include defining its anatomical attachment sites on the femur, tibia, and lateral meniscus and its precise role in knee biomechanics; evaluation of its histological composition, as well as the consequences of its insufficiency. Also, it is important to make a precise diagnosis (clinical, radiological - MRI, US), to study the natural healing potential of the ALL, the exact operative indications, and the best surgical reconstruction technique.

\section{CONFLICT OF INTEREST}

Nothing to declare.

\section{REFERENCES}

1. Claes S, Vereecke E, Maes M, Victor J, Verdonk P, Bellemans J. Anatomy of the anterolateral ligament of the knee. J Anat. 2013;223:321-328.

2. Segond P. Recherches cliniques et expérimentales sur les epanchements sanguins du genou par entorse. Progre`s Med. 1879;7:297-341.

3. Last RJ. Some anatomical details of the knee joint. J Bone Joint Surg Br. 1948;30B:683-688.

4. Hughston JC, Andrews JR, Cross MJ, Moschi A. Classification of the knee ligament instabilities. Part II. The lateral compartment. J Bone Joint Surg Am. 1976;58:173-179.

5. Muller W. The Knee. Springer-Verlag; 1982.

6. Terry GC, Hughston JC, Norwood LA. The anatomy of the iliopatellar band and iliotibial tract. Am J Sports Med. 1986;14:39-45.

7. LaPrade RF, Gilbert TJ, Bollom TS, Wentorf F, Chaljub G. The magnetic resonance imaging appearance of individual structures of the posterolateral knee. A prospective study of normal knees and knees with surgically verified grade III injuries. Am J Sports Med. 2000;28:191-199.

8. Vieira EL, Vieira EA, da Silva RT, Berlfein PA, Abdalla RJ, Cohen M. An anatomic study of the iliotibial tract. Arthroscopy. 2007;23:269-274.

9. Cruells Vieira EL, Vieira EÁ, Teixeira Da Silva R, et al. An anatomic study of the iliotibial tract. Arthroscopy. 2007;23:269-274.

10. Dodds A, Halewood C, Gupte C, et al. The anterolateral ligament anatomy, length changes and association with the Segond fracture. Bone Joint J. 2014;96:325-331.

11. Ingham SJ, de Carvalho RT, Martins CA, et al. Anterolateral ligament anatomy: a comparative anatomical study. Knee Surg Sports Traumatol Arthrosc. 2017;25:1048-1054.

12. Kittl C, El-Daou H, Athwal KK, et al. The role of the anterolateral structures and the $A C L$ in controlling laxity of the intact and $A C L$-deficient knee. Am J Sports Med. 2016;44:345-354.

13. MusahI V, Rahnemai-Azar AA, van Eck CF, Guenther D, Fu FH. Anterolateral ligament of the knee, fact or fiction? Knee Surg Sports Traumatol Arthrosc. 2016;24:2-3

14. Daggett M, Ockuly AC, Cullen M, et al. Femoral origin of the anterolateral ligament: an anatomic analysis. Arthroscopy. 2016;32:835-841.
15. Vincent JP, Magnussen RA, Gezmez F, et al. The anterolateral ligament of the human knee: An anatomic and histologic study. Knee Surg Sports Traumatol Arthrosc. 2012;20:147-152

16. Stijak L, Bumbasirevic M, Radonjic V, et al. Anatomical description of the anterolateral ligament of the knee. Knee Surg Sports Traumatol Arthrosc. 2016;24:2083-2088.

17. Parker M, Smith HF. Anatomical variation in the anterolateral ligament of the knee and a new dissection technique for embalmed cadaveric specimens. Anat Sci Int. 2016. doi:10.1007/s12565-016-0386-2

18. Roessler PP, Schüttler KF, Stein T, et al. Anatomic dissection of the anterolateral ligament (ALL) in paired fresh-frozen cadaveric knee joints. Arch Orthop Trauma Surg. 2017;137:249

19. Helito CP, Demange MK, Bonadio MB, Tirico LEP, Gobbi RG, Pecora JR, Camanho GL. Anatomy and histology of the knee anterolateral ligament. Orthop J Sports Med. 2013;1:1-5.

20. Tillmann B. Binde- und Stützgewebe. In: Leonhard H, Tillmann B, Töndury G, Zilles K, (Hrsg) Bewegungsapparat. Rauber/Kopsch, Anatomie des Menschen, Lehrbuch und Atlas, Bd. I. Thieme, Stuttgart; 1998.

21. Petersen W, Zantop T. Anatomie der lateralen und medialen Stabilisatoren des Kniegelenks. Arthroskopie. 2017;30:4

22. Caterine S, Litchfield R, Johnson M, Chronik B, Getgood A. A cadaveric study of the anterolateral ligament: re-introducing the lateral capsular ligament. Knee Surg Sports Traumatol Arthrosc. 2015;23:3186-3195.

23. Kosy JD, Sonui A, Venkatesh R, Mandalia VI. The anterolateral ligament of the knee: unwrapping the enigma. Anatomical study and comparison to previous reports. J Orthopaed Traumatol. 2016;17:303-308.

24. Sonnery-Cottet B, Daggett M, Fayard JM, et al. Anterolateral Ligament Expert Group consensus paper on the management of internal rotation and instability of the anterior cruciate ligament-deficient knee. J Orthop Traumatol. 2017. doi: 10.1007/s10195-017-0449-8.

25. Kennedy Ml, Claes S, Fuso FA, et al. The anterolateral ligament: an anatomic, radiographic, and biomechanical analysis. Am J Sports Med. 2015;43:1606-1615.

26. Van der Watt L, Khan M, Rothrauff BB, et al. The structure and function of the anterolateral liga- ment of the knee: a systematic review. Arthroscopy. 2015;31:569-582

27. Pomajzl R, Maerz T, Shams $\mathrm{C}$, et al. A review of the anterolateral ligament of the knee: current knowledge regarding its incidence, anatomy, biomechanics, and surgical dissection. Arthroscopy. 2015;31:583-591.

28. Guenther D, Irarrazaval S, Griffith C, Musahl V, Debski RE. Anatomy and Function of the anterolateral capsule structures. Rotatory Knee Instability. An Evidence Based Approach. Springer. 2016

29. Musahl V, Bedi A, Citak M, O'Loughlin P, Choi D, Pearle AD. Effect of singlebundle and double-bundle anterior cruciate ligament reconstructions on pivot-shift kinematics in anterior cruciate ligament- and meniscus-deficient knees. Am J Sports Med. 2011;39:289-295.

30. Shybut TB, Vega CE, Haddad J, et al. Effect of lateral meniscal root tear on the stability of the anterior cruciate ligament-deficient knee. Am J Sports Med. 2015;43:905-911.

31. Terry GC, Norwood LA, Hughston JC, Caldwell KM. How iliotibial tract injuries of the knee combine with acute anterior cruciate ligament tears to influence abnormal anterior tibial dis- placement. Am J Sports Med. 1993;21:55-60.

32. Parsons EM, Gee AO, Spiekerman C, Cavanagh PR. The biomechanical function of the ante- rolateral ligament of the knee. Am J Sports Med. 2015;43:669-674

33. Rasmussen MT, Nitri M, Williams BT, et al. An in vitro robotic assessment of the anterolateral ligament, part 1: Secondary role of the anterolatera ligament in the setting of an anterior cruciate ligament injury. Am J Sports Med. 2016;44:585-592.

34. Sonnery-Cottet B, Lutz C, Daggett M, et al. The involvement of the anterolateral ligament in rotational control of the knee. Am J Sports Med. 2016;44:1209-1214.

35. Thein R, Boorman-Padgett J, Stone K, Wickiewicz TL, Imhauser CW, Pearle $A D$. Biomechanical assessment of the anterolateral ligament of the knee: a secondary restraint in simulated tests of the pivot shift and of anterior stability. J Bone Joint Surg Am. 2016;98:937-943.

36. Drews, B.H., Kessler, O., Franz, W., Dürselen, L., Freutel, M. Function and strain of the anterolateral ligament part I: biomechanical analysis. Knee Surg Sports Traumatol Arthrosc. 2017;25:1132-1139.

37. Spencer L, Burkhart TA, Tran MN, et al. Biomechanical analysis of simulated clinical testing and reconstruction of the anterolateral ligament of the knee. Am J Sports Med. 2015;43:2189-2197. 
38. Halewood C, Amis AA. Clinically relevant biomechanics of the knee capsule and ligaments. Knee Surg Sports Traumatol Arthrosc. 2015;23:2789-2796.

39. Monaco E, Ferretti A, Labianca L, et al. Navigated knee kinematics afte cutting of the ACL and its secondary restraint. Knee Surg Sports Trau matol Arthrosc. 2012;20:870-877.

40. MJ Feucht, M Zens, KH Frosch, R Akoto, NP Südkamp, P Niemeyer. The anterolateral ligament of the knee: anatomy, biomechanics, and clinical implications. Current Orthopaedic Practice. 2016;27:247-253.

41. Porrino J Jr, Maloney E, Richardson M, et al. The anterolateral ligament of the knee: MRI appearance, association with the Segond fracture, and historical perspective. AJR Am J Roentgenol. 2015;204:367-373.

42. Campos JC, Chung CB, Lektrakul N, et al. Pathogenesis of the Segond fracture: anatomic and MR imaging evidence of an iliotibial tract or anterior oblique band avulsion. Radiology. 2001;219:381-386.

43. De Maeseneer M, Boulet C, Willekens I, et al. Segond fracture: involvement of the iliotibial band, anterolateral ligament, and anterior arm of the biceps femoris in knee trauma. Skeletal Radiol. 2015;44:413-421.

44. Claes S, Luyckx T, Vereecke E, et al. The Segond fracture: a bony injury of the anterolateral ligament of the knee. Arthroscopy. 2014;30:1475-1482.
45. Dodds AL, Gupte CM, Neyret P, et al. Extra-articular techniques in anterior cruciate ligament reconstruction: a literature review. J Bone Joint Surg Br. 2011;93:1440-1448.

46. Bedi A, Musahl V, Lane C, Citak M, Warren RF, Pearle AD. Latera compartment translation predicts the grade of pivot shift: a cadaveric and clinical analysis. Knee Surg Sports Traumatol Arthrosc. 2010;18:1269-1276.

47. Kittl C, Halewood C, Stephen JM, et al. Length change patterns in the lateral extra-articular structures of the knee and related reconstructions. Am J Sports Med. 2015;43:354-362.

48. Sonnery-Cottet B, Thaunat M, Freychet B, et al. Outcome of a combined anterior cruciate ligament and anterolateral ligament reconstruction technique with a minimum 2-year follow-up. Am J Sports Med. 2015:43:1598-1605.

49. Helito CP, Bonadio MB, Gobbi RG, et al. Combined intra- and extra-articular reconstruction of the anterior cruciate ligament: the reconstruction of the knee anterolateral ligament. Arthrosc Tech. 2015;4:e239-e244.

50. Wagner M, Weiler A. Anterolaterale Stabilisierung. Arthroskopie. 2014;27:198-201.

51. Wagner M, Kittl C, Weiler A. Anterolaterale Stabilisierung. Arthroskopie. 2017:30:44-48 